\title{
An Unusual Presentation of Foreign Body Granuloma of Ankle Mimicking a Neoplastic Lesion
}

\author{
Mohit Dadlani ${ }^{1}$, Ankit Jaiswal², Kiran Saoji ${ }^{3}$, Gajanan Pisulkar ${ }^{4}$ \\ 1, 2,3,4 Department of Orthopaedics, Jawaharlal Nehru Medical College, Datta Meghe Institute of Medical Sciences \\ (Deemed to Be University), Sawangi (Meghe), Wardha, Maharashtra, India.
}

\section{INTRODUCTION}

Granulomas of foreign body can mimic features of neoplasia, especially when history and odd location create diagnostic confusion. Penetrating foot wounds are not that unusual. Thorns or wood particles that are stored in the foot are the cause of granuloma of the alien body. Later, soft tissue and osseous complications can arise from an untreated retained foreign body.

\section{PRESENTATION OF CASE}

We report a case of a 50-year-old male who came to the out-patient department (OPD) with pain and swelling over right ankle (Figure 1) for last 6 months and the swelling was progressively increasing in size and there was history of trivial trauma to right ankle around 10 months ago. The pain was dull aching in nature and gradually progressive in intensity. The pain was aggravated by walking and relieved on taking rest and medications. The patient was initially treated conservatively with analgesics which gave him symptomatic relief for some period of time.

$\mathrm{X}$ ray was suggestive of a soft tissue swelling over the posterolateral aspect of right ankle. Magnetic resonance imaging (MRI) was done which suggested of numerous similar sized intra-articular loose bodies of variable signal intensities and lesion was also extending into the subcutaneous plane suggestive of synovial chondromatosis. For further confirmation, fine needle aspiration cytology (FNAC) from the lesion was done which revealed fibro collagenous tissue with cystic spaces filled with haemorrhage and chronic inflammatory exudate suggestive of infected organized haematoma and/or foreign body granuloma. In the time of 6-month followup after removal of the mass, no recurrence of granuloma was reported. The technique for assessing certain cases of foot swelling that can resemble neoplasms has been reviewed.

An untreated retained foreign body which may later cause soft tissue and osseous complications was successfully managed with removal of same along with excision of foreign body granuloma. Early identification, detection of causative agent, radiologic evaluation, close follow up and intervention is essential to reduce short- and longterm adverse effects.

Granuloma following skin penetration trauma is a tissue response of preserved foreign bodies. When the patient has non-specific signs such as discomfort and/or swelling without knowing prior injuries, the diagnosis of preserved foreign bodies can be exceedingly difficult. Penetrating lower limb wounds are not that rare.

\author{
Corresponding Author: \\ Mohit Dadlani, \\ Junior Resident, \\ Department of Orthopaedics, \\ Datta Meghe Institute of \\ Medical Sciences, \\ Sawangi (Meghe), Wardha, \\ Maharashtra, India. \\ E-mail: dadlanimohit786@gmail.com
}

DOI: $10.14260 /$ jemds/2021/322

How to Cite This Article:

Dadlani M, Jaiswal A, Saoji K, et al. An unusual presentation of foreign body granuloma of ankle mimicking a neoplastic lesion. J Evolution Med Dent Sci 2021;10(20):1547-1550, DOI: $10.14260 /$ jemds/2021/322

Submission 01-12-2020,

Peer Review 11-03-2021,

Acceptance 19-03-2021,

Published 17-05-2021.

Copyright (C) 2021 Mohit Dadlani et al. This is an open access article distributed under Creative Commons Attribution License [Attribution 4.0 International (CC BY 4.0)] 
Thorns or wood particles that are stored in the leg can lead to formation of granuloma of the foreign body. Masses of soft tissue around the foot and ankle are frequent. While benign lesions are twice as common as malignant lesions, they only account for one third of all lesions. The key goal of this article is to suggest a comprehensive approach to the differential diagnosis of foot and ankle soft tissue tumours based on clinical history and physical examination, patient age, location of lesions and mass MRI characteristics.

\section{DISCUSSION OF MANAGEMENT}

$\mathrm{X}$ ray of the right ankle anteroposterior and lateral view (Figure 2) taken on OPD presentation showed a soft tissue swelling over the posterolateral aspect of ankle with no bony involvement. The patient was then admitted, and MRI was done (Figure 3) which was suggestive of numerous similar sized intra-articular loose bodies of variable signal intensities and the lesion extending into the subcutaneous plane suggestive of synovial chondromatosis.

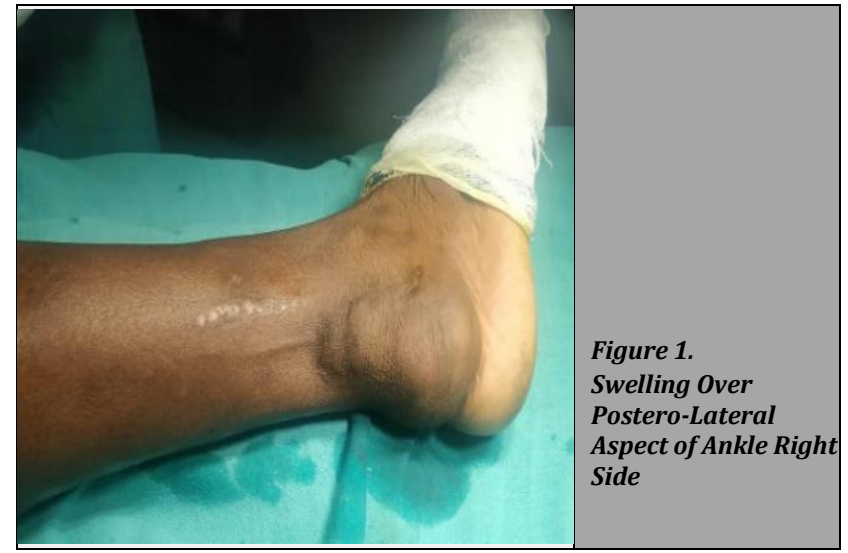

But the diagnosis on MRI was not so confirmative, that's why fine needle aspiration cytology (FNAC) from the lesion was done which revealed fibro collagenous tissue with cystic spaces filled with haemorrhage and chronic inflammatory exudate suggestive of infected organised haematoma and/or foreign body granuloma.

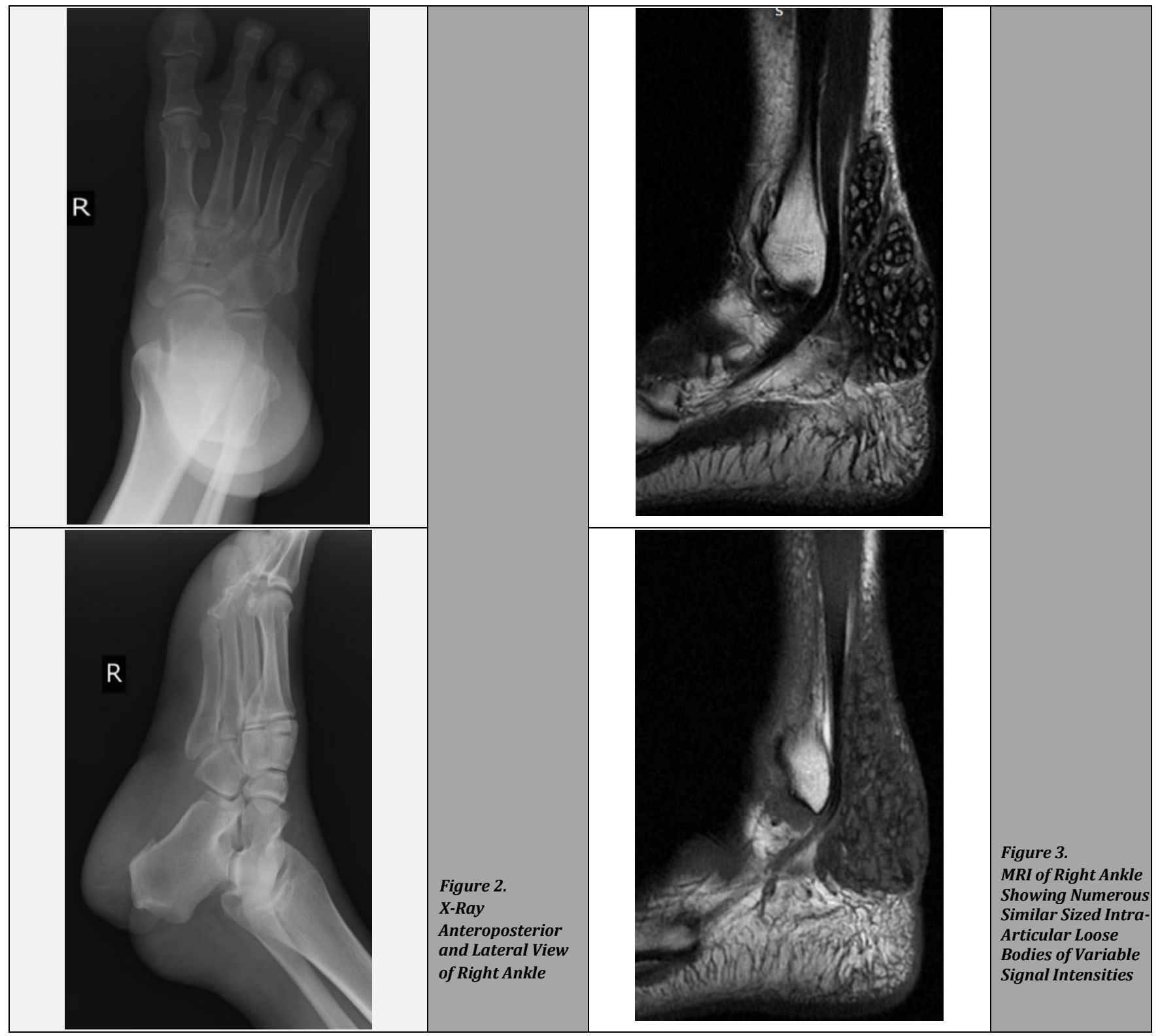



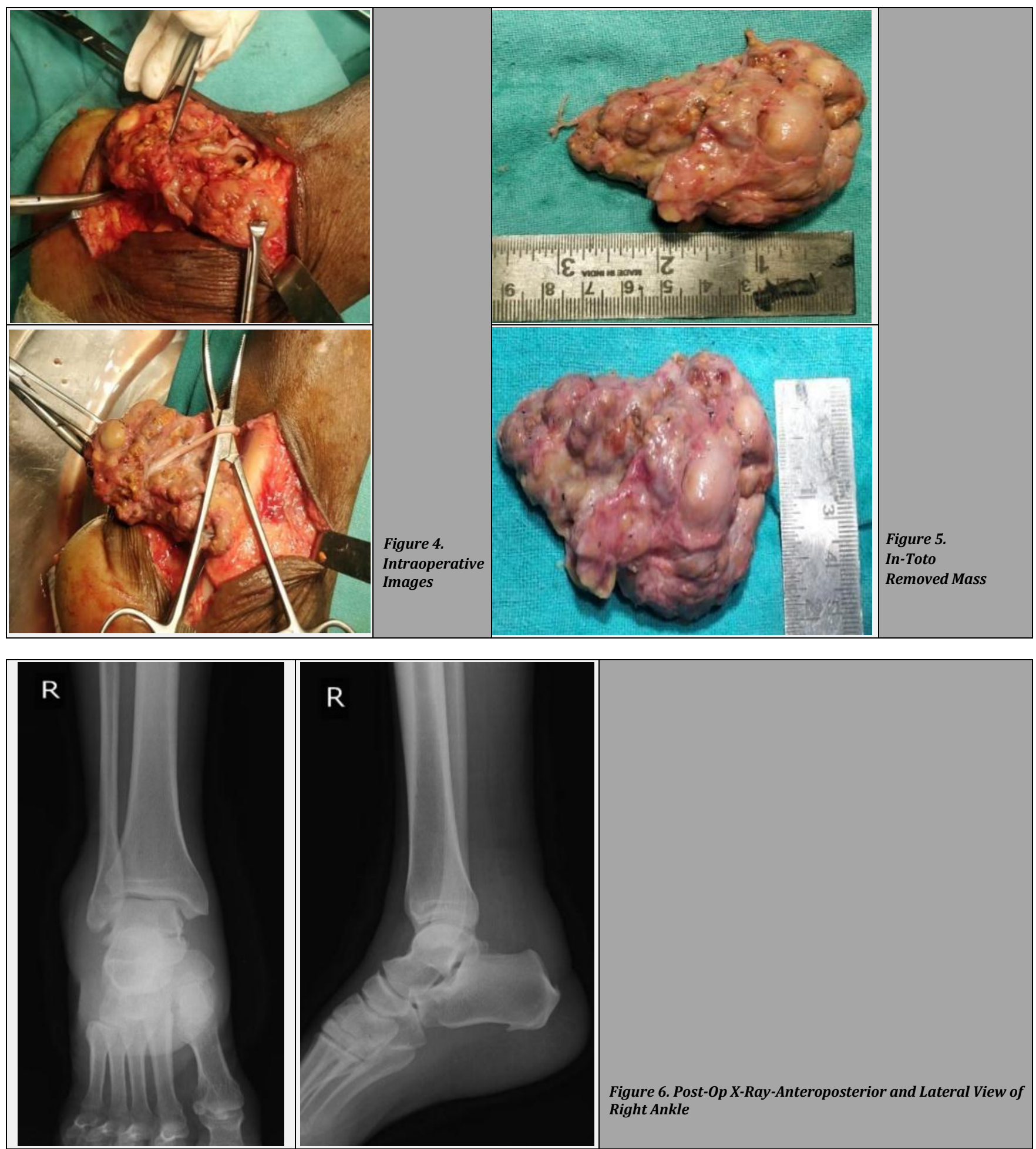

The patient was planned to be taken up for excision of the mass from right ankle under spinal anaesthesia. Complete preoperative workup was done and the patient was taken up for surgery on being deemed fit. The patient was taken up for surgery and the whole mass was exposed by a postero-lateral incision (Figure. 4) and was removed in toto (Figure. 5) preventing damage to the surrounding soft tissues and the foreign body was searched but no foreign body was found, and the procedure was uneventful.

The patient was stable post-operatively and was mobilized from post-operative day 2 after checking of the dressing and the sutures were healthy too. The post-operative $\mathrm{x}$ ray was also done (Figure 6) in which the soft tissue swelling was not

evident. Pain had reduced and patient was discharged after suture removal.

\section{DISCUSSION}

More generally, preserved foreign bodies in the foot arise after puncture wounds in babies. Glass, metal objects and organic compounds are part of them. Mostly on clear x rays, glass, ceramic, and metal foreign bodies are marked. On the other hand, organic compounds, and plastic face diagnostic difficulties when they do not appear on clear x-ray. ${ }^{1}$ The symptoms of thorn on soft and bony tissues include foreign 
body cysts, bursitis, tenosynovitis, synovitis, monoarthritis, and tumour-like bone lesions. ${ }^{2-4}$

Hand, knee, and foot fractures (meta-tarsal, cuneiform, cuboid, and phalangeal lesions) are commonly recorded, and injuries may be limited to soft tissues or intra-articular.1,5 The estimated time from injury to diagnosis of bone lesions varies from 4 months to 20 years, and the injury may have been completely neglected by both the child and the family. This will lead to a clinically significant delay in making the right diagnosis. ${ }^{13,5}$ If the foreign body is not taken out or is not phagocytosed through the acute allergic response, fibrous tissue is capsulated and granuloma forms. ${ }^{2}$ The bony lesion caused mainly by thorn or wood splinter tends to be the result of an inflammation that is seen in osteo-lysis or periostitis and both. 5

If there is no recognition of previous skin puncture history and if the foreign body is radiolucent, bone reaction x-ray presence may be a little misleading and can also look like neoplasm. Differential diagnosis of osteoid osteoma, chronic and acute osteomyelitis, tuberculosis granuloma, bone cyst, aneurysmal bone cyst, and others like bony responses to unrecognized organic foreign bodies should be made. ${ }^{2,3}$

Prolonged morbidity can be the source of preserved nonradiopaque foreign bodies inside soft tissues. For standard $\mathrm{x}$ rays, identification and translation are challenging challenges. Ultrasonography (USG), computed tomography (CT) and magnetic resonance imaging (MRI) are other forms of measurement, but both CT and MRI are costly and not always available. ${ }^{1,6}$ Any imaging technique cannot reliably detect splinters that are found to be immersed for less than 3 days or those found near the bone.5 USG is more receptive and relevant to the detection and localization of foreign bodies to be used in the assessment of clinically suspected and preserved non-radiopaque foreign bodies in limb soft tissue. ${ }^{6}$ Excised foreign body provides for symptomatic and radiographic recovery.

\section{CONCLUSIONS}

In the absence of definite history of wounds, differential diagnosis of lytic bony lesions, organic foreign body lesions should be considered, so that needless delays and potentially risky procedures can be avoided.

Financial or other competing interests: None.

Disclosure forms provided by the authors are available with the full text of this article at jemds.com.

\section{REFERENCES}

[1] Harris EJ. Retained hawthorn fragment in a child's foot complicated by infection: diagnosis and excision aided by localization with ultrasound. J Foot Ankle Surg 2009;49(2):161-5.

[2] Bouajina E, Harzallah L, Ghannouchi M, et al. Foreign body granuloma due to unsuspected wooden splinter. Joint Bone Spine 2006;73(3):329-31.

[3] Verma D, Mittal S, Kapoor R, et al. Neglected thorn injury mimicking tuberculosis in wrist of 20 year old male : a case report. Journal of Bone and Joint Diseases 2019;34(3):35-7.

[4] Barry M, Maffulli N, Good C. The missed thorn. Acta Orthop Belg 1992;58(4):468-70.

[5] Durr HR, Stabler A, Muller PE, et al. Thorn-induced pseudotumor of the metatarsal. A case report. J Bone Joint Surg Am 2001;83(4):580-5.

[6] Shrestha D, Sharma UK, Mohammad R, et al. The role of ultrasonography in detection and localization of radiolucent foreign body in soft tissues of extremities. JNMA J Nepal Med Assoc 2009;48(173):5-9. 